\title{
Neurological disorders and barriers for neurological rehabilitation in rural areas in Uttar Pradesh: A cross-sectional study
}

\author{
Hirdesh Kumar, Nalina Gupta \\ Department of Physiotherapy, College of Applied Education and Health Sciences, Meerut, Uttar Pradesh, India
}

\begin{abstract}
Background: In India, the majority of individuals with neurological disorders are rural based and cannot even afford the cost of rehabilitation. At the same time, we do not have barrier free environment in India. Aim: This study attempts to find out the neurological disorders and barriers for neurological rehabilitation in rural areas in Uttar Pradesh, India. Setting: Rural areas in Uttar Pradesh, India. Design: It is a cross-sectional study. Materials and Methods: The study was done by means of an interview method using a questionnaire. The rural areas in Uttar Pradesh were visited personally and a data from 201 individuals was collected. Statistical Analysis Used: Data analysis was done by using descriptive statistics. Results: Out of 201 individuals, $76.6 \%(n=154)$ individuals were with polio, 12.9\% $(n=26)$ were with cerebral palsy, $7.9 \%(n=16)$ were with stroke and $2.4 \%(n=5)$ were with spinal cord injury. Reasons for not taking the treatment/discontinuation of treatment were financial problem (44\%), lack of awareness (43\%), family negligence (6\%), transportation problem (3.5\%) and other environmental barriers (1\%). Conclusion: In our study, we found polio to be the most prevalent disorder followed by Cerebral Palsy, Stroke and Spinal Cord Injury. Financial problem was the major barrier for neurological rehabilitation followed by lack of awareness, family negligence and transportation problem.
\end{abstract}

Key words: Disability, environmental barriers, neurological disorders, poverty, rehabilitation

\section{Introduction}

A neurological disorder is a disorder of the body's nervous system. Structural, biochemical or electrical abnormalities in the brain, spinal cord, or in the nerves leading to or from them, can result in symptoms such as paralysis, muscle weakness, poor coordination, loss of sensation, seizures, confusion, pain and altered levels of consciousness. ${ }^{[1]}$ Neurological disorders can create serious obstacles to community reintegration. Community reintegration is an important aspect to be looked at once the patient returns home after an injury. ${ }^{[2]}$

\begin{tabular}{|l|l|}
\hline \multicolumn{2}{|c|}{ Access this article online } \\
\hline Quick Response Code: & Website: \\
\hline & www.ruralneuropractice.com \\
\cline { 2 - 2 } & \\
\hline & \\
\hline
\end{tabular}

The sociodemographic and epidemiological transition in developing countries has changed the morbidity and mortality pattern among communities. This has brought non-communicable diseases to the forefront of the health-care delivery system. Within this group, neurological disorder constitute a significant proportion affecting morbidity, mortality, disability and quality of life. ${ }^{[3,4]}$ However, neurological services are slowly expanding in India and given the vast population, there is an urgent need for reorganization of the services with optimal utilization of existing specialized manpower.

In order to plan services in a socioculturally appropriate and cost-effective manner, epidemiological data on neurological disease form a basic prerequisite. Earlier studies undertaken in India were on a smaller scale and/ or involved certain specific ethnic population. In India majority of individuals with neurological disorders are rural based and cannot even afford the cost of rehabilitation. At the same time, we do not have barrier free environment.

\section{Address for correspondence:}

Mr. Hirdesh Kumar, Department of Physiotherapy, College of Applied Education and Health Sciences, Gangotri, Roorkee Road, Meerut - 250 001, Uttar Pradesh, India. E-mail: heryshgr@gmail.com 
A study by Sekaran et al in rural South India showed that there is decline in community reintegration of spinal cord injured patients in rural south India. Architectural and environmental barriers, poor socioeconomic status and comorbidities significantly affected the level of community participation. ${ }^{[5]}$

Samuelkamaleshkumar et al in their study found that Persons with SCI in rural South India who have completed comprehensive, mostly self-financed, rehabilitation with an emphasis on achieving functional ambulation, family support, and self-employment and who attend a regular annual follow-up show a high level of community reintegration in physical independence, social integration, and cognitive independence. CHART scores in the domains of occupation, mobility and economic self-sufficiency showed lower levels of community reintegration. ${ }^{[6]}$

Most of the studies regarding environmental barriers and community reintegration of individuals with neurological disorders (especially that of spinal cord injury) have taken place in South India. There is scant literature on the same in North India. Thus, we chose rural areas of Uttar Pradesh in North India in our study.

Uttar Pradesh is a state located in the northern part of India. With a population of over 199 million people, it is India's most populous state, as well as the world's most populous subnational entity. Were it a nation in its own right, Uttar Pradesh would be the world's fifth most populous country ahead of Pakistan. Uttar Pradesh is the second largest state-economy in India contributing $8.34 \%$ to India's total GDP in the financial year 2010. ${ }^{[7]}$

This study attempts to find out the presence of neurological disorders and barriers for neurological rehabilitation in rural areas in Uttar Pradesh.

\section{Materials and Methods}

\section{Study design - It is a cross- sectional study}

The sample was collected from rural areas in Uttar Pradesh. The villages visited were- Daurala, Bharala, RuhasaLabarJalalpur, Kanoda, Baheta, Samoli Salempur, Samatal Sahapur Tigri, Tigri, Dodaura, Milak, Noorpur, Mahamoodpur, Bastoor, Milak Nanpur and Nanpur. A total of 201 individuals were surveyed.

\section{Procedure}

The study was reviewed and approved by research committee/ethics board of the college. The study was done by means of an interview method using a questionnaire.
This questionnaire was drafted by my guide and by myself. The questionnaire consisted of, 1.demographic information; name, age, gender, address, occupation 2. presence of neurological condition; stroke, spinal cord injury, polio, cerebral palsy, others 3.treatment taken/ discontinuation of treatment; whether they had taken any treatment, whether they were still continuing with the treatment, reasons for discontinuation of treatmentfinancial problem, lack of awareness, family negligence, transport problem, others 4 . employment; were they employed 5. life satisfaction; were they satisfied with their quality of life.

This questionnaire was distributed to all the faculty members and the clinical physiotherapists working in the institute and required modifications were made based on their feedbacks. Then it was pilot tested on five individuals in the rural area and further modification was done.

For data collection, personal visits were made to rural areas in Uttar Pradesh. The information regarding the individuals with neurological disorders was obtained from the head ("Sarpanch") of that particular village and all the subjects with neurological impairments were included in the study.

All these subjects were visited at their door steps. The consent to participate in the study was taken from these individuals and they were informed about the study properly prior to data collection. All these identified individuals were interviewed based on the questions asked in the questionnaire. The questionnaire was filled by the author based on the information obtained.

\section{Data analysis}

Data was analyzed using descriptive statistics.

\section{Results}

\section{Demographic characteristics}

The demographic characteristics are shown in Table 1.

Age: Majority of the individuals were in the age group between 11 and 20 years $(41.5 \%)$ followed by that between 21 and 30 years (24\%) and 0 and 10 years (12.5\%).

Gender: $71.5 \%$ of individuals were males and $28.5 \%$ were females

Occupation: Majority of the individuals who were surveyed were students followed by manual workers and housewives. 
Table 1: Demographic characteristics $(\mathrm{n}=\mathbf{2 0 1})$

\begin{tabular}{lc}
\hline Demographics & Percentage (\%) \\
\hline Age (in years) & 12.5 \\
$0-10$ & 41.5 \\
$11-20$ & 24 \\
$21-30$ & 6.5 \\
$31-40$ & 4 \\
$41-50$ & 5.5 \\
$51-60$ & 5 \\
$61-70$ & 1 \\
$71-80$ & 0.5 \\
$81-90$ & \\
Gender & 71.5 \\
Male & 28.5 \\
Female & \\
Occupation & 26.5 \\
Student & 10 \\
Worker & 9 \\
House-wife & 3 \\
Shopkeeper & 2 \\
Tailor & 1 \\
Farmer & 1 \\
Barber & 0.5 \\
Gardner & 0.5 \\
Cobbler & 0.5 \\
Security guard & 0.5 \\
Teacher & 0.5 \\
Carpenter & 45 \\
No occupation &
\end{tabular}

Treatment: Only $31.5 \%$ of individuals had taken treatment. Out of these individuals, only $43 \%$ of individuals were continuing with any form of treatment like medicines and massage. None of them were undergoing rehabilitation.

\section{Prevalence of neurological disorders}

Out of 201 individuals, $76.6 \%$ ( $\mathrm{n}=154)$ individuals were with polio, $12.9 \%(n=26)$ were with cerebral palsy, $7.9 \%$ $(n=16)$ were with stroke and $2.4 \%(n=5)$ were with spinal cord injury, as depicted in Figure 1.

\section{Barriers for neurological rehabilitation}

Reasons for not taking the treatment/discontinuation of treatment were financial problem $(44 \%)$, lack of awareness ( $43 \%)$, family negligence $(6 \%)$, transportation problem (3.5\%) and other environmental barriers (1\%), as depicted in Figure 2.

\section{Discussion}

This was a cross-sectional study to find out the prevalence of neurological disorders and barriers

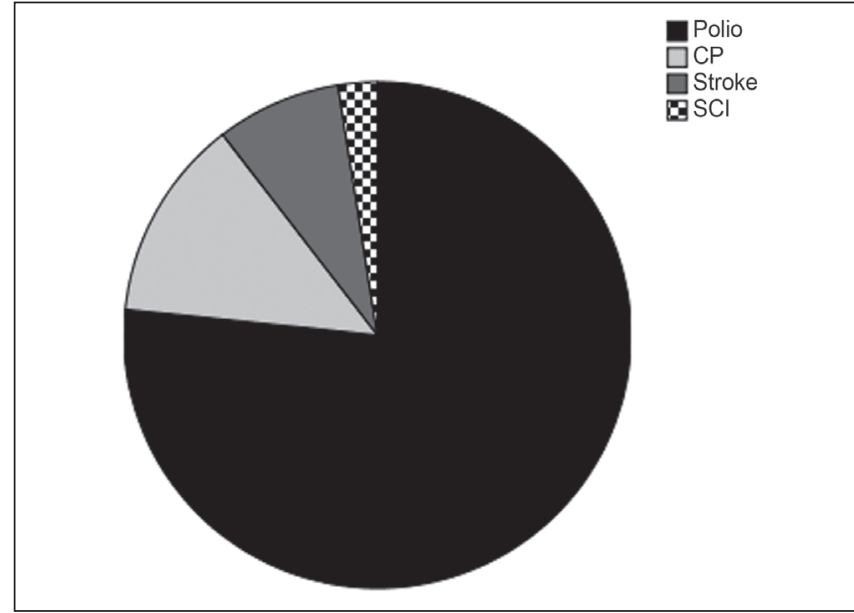

Figure 1: Neurological disorders among subjects $(n=201)$

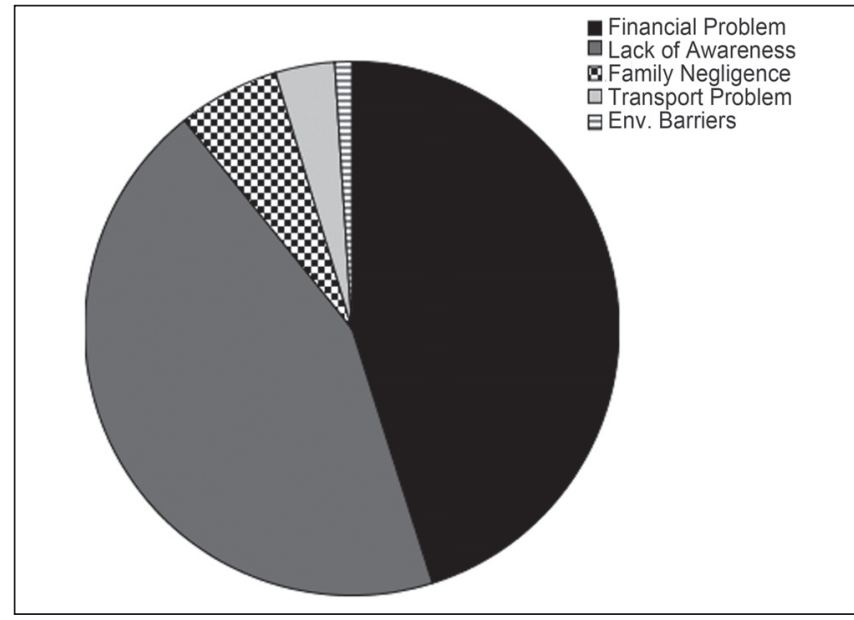

Figure 2: Barriers for neurological rehabilitation

for neurological rehabilitation in rural areas in Uttar Pradesh. In our study, we found polio to be the most prevalent disorder followed by cerebral palsy, stroke and spinal cord injury.

The WHO along with the Delhi government carried out, the environment surveillance under the National Polio Surveillance Project (NPST) 2010 till December. According to the WHO, wild polio virus was present before the common wealth games in October 2010. The surveillance was done at 5 places along the Yamuna. According to Mr. Jafari, both Delhi and Mumbai, are the most frequently visited by migrant laborers, are high risk areas for repeated introduction of polio virus and are therefore covered in all subnational immunization rounds along with polio endemic state Uttar Pradesh and Bihar. ${ }^{[8]}$

India, Pakistan, Afghanistan and Nigeria are four polio endemic countries in the world. India has reported drop of $90 \%$ of polio cases with only $42 \%$ cases been reported 
2010. ${ }^{[8]}$ At national level there has been decrease in the number of polio cases from 874 polio cases in the year 2007 to 741 polio cases in the year 2009 and 21 cases in 2010 till $16^{\text {th }}$ June. ${ }^{9}$ Out of 741 polio cases reported at the National Level in the year 2009, Uttar Pradesh accounted for 602 cases and Bihar for 117 cases and Delhi, due to its close proximity to UP and high inflow of floating population from UP and Bihar (settling in slums eventually) experiences the additional responsibility of keeping a complete protection coverage even to this population on a regular basis..$^{[9]}$

In our study, we also found that financial problem was the major barrier for neurological rehabilitation followed by lack of awareness, family negligence and transportation problem. According to 2005 World Bank estimate, $42 \%$ of India's population falls below the international poverty line and as mentioned in BBC News Night in October 2006 , about 300 million people in are living on less than 50 pence per day. This would be the main roadblock for neurological rehabilitation. ${ }^{[10]}$ Architectural and environmental barriers, poor socioeconomic status and comorbidities significantly affect the level of community participation. ${ }^{[5]}$

India has some 40 to 80 million disabled people. At least one in 12 households has a member with disability. Illiteracy, unemployment and poverty among the disabled are high. ${ }^{[11]}$ According to census 2001, there are 21.9 million people with disabilities in India which constitute $2.13 \%$ of total population. Seventy-five percent of persons with disabilities live in rural areas, $49 \%$ population is literate and only $34 \%$ are employed. ${ }^{[12]}$

Despite these staggering statistics, India like other developing countries invests most of its health care budget in preventing communicable diseases. Disability rehabilitation is a luxury where inroads can be made only when infectious diseases are controlled and we can achieve total immunization. There is a strong correlation between disability and poverty. Poverty leads to increased disability and disability lead to increased poverty. Thus, a majority of people with disabilities have lack of access to health care and even basic rehabilitation. ${ }^{[12]}$

In our study, we found that $45 \%$ of individuals were having no occupation. $26.5 \%$ of individuals were students and among those who were having occupation, majority of them were manual workers, shopkeepers, farmers, barbers, cobbler, security guard, individual working in garden, tailor and carpenter. Only one of them was a teacher. According to conservative estimates, there are 70 million people with disability in India. But there is only minuscule percentage of the population that has been seen in main stream of any aspect of life in the country, be it the work force, education and anything else. The reason for this would be the lack of access, primarily in the built environment. ${ }^{[13]}$

\section{Conclusions}

In our study, we found polio to be the most prevalent disorder followed by cerebral palsy, stroke and spinal cord injury. Financial problem was the major barrier for neurological rehabilitation followed by lack of awareness, family negligence and transportation problem.

\section{Limitation of the study}

The study is only limited to Meerut and Moradabad District Rural areas of Uttar Pradesh.

The standardized questionnaire that looks at environmental barriers and classification of neurological impairments was not used in the study, which would have greatly enhanced the quality of this research.

Full list of environmental factors was not considered as well as facilitators were not looked at in the study.

Ethnicity has not been addressed in the study.

\section{Clinical implication}

- Government should come up with the strategies to remove barriers for neurological rehabilitation.

- Community-based programs should be implemented on a regular basis.

- Regular follow-ups should be given emphasis.

- Steps should be taken to reach the maximum number of children $<5$ years of age through NID/SNID booths approach. ${ }^{[14]}$

- House-to-house activity should be planned to administer polio drops. ${ }^{[14]}$

- To create awareness amongst community regarding polio as well as other vaccines. ${ }^{[14]}$

\section{Future research}

- A large sample size should be included.

- Rural areas of other states of India should also be covered.

- The standardized questionnaire that looks at environmental barriers and classification of neurological impairments should be used in the future study.

- Full list of environmental factors and facilitators should be added in the future study.

- Ethnicity can be added in the future study.

- International classification of functioning, health and 


\section{disability ICF should be used in the future study.}

\section{References}

1. Neurological Disorder. Available from: http://en.wikipedia.org/wiki/ Neurological_disorder. [Last accessed on 2011 Mar 18].

2. Sandberg MA, Bush SS, Martin T. Beyond diagnosis: Understanding the healthcare challenges of injured veterans through the application of the International Classification of Functioning, Disability and Health (ICF). Clin Neuropsychol 2009;23:1416-32

3. Chandre V, Pandav CS. The importance of non-communicable disease in developing countries (editorial). Ind J Com Med 1987;12:178-80.

4. Gourie-Devi M. Can India offord neuroepidemiology. Neurol India 1987;35:125-7.

5. Sekaran P, Vijayakumari F, Hariharan R, Zachariah K, Joseph SE, Kumar RK. Community reintegration of spinal cord-injured patients in rural south India. Spinal Cord 2010;48:628-32.

6. Samuelkamaleshkumar S, Radhika S, Cherian B, Elango A, Winrose W, Suhany BT, et al. Community reintegration in rehabilitated South Indian persons with spinal cord injury. Arch Phys Med Rehabil 2010;91:1117-21.

7. Uttar Pradesh. Available from: http://en.wikipedia.org/wiki/Uttar_ Pradesh. [Last accessed on 2011 Mar 18].

8. Qureshi A. World Health organization finds polio virus in Delhi survage.
Available from: http://www, disability India.com] html \news.html. [Last accessed on 2011 Mar 18].

9. Introductory note on Pulse Polio Programme 2010-2011 with proposed newer initiatives- An Appraisal. Available from: http://www.google. co.in $/$ search?q $=\% 22$ POLIO $\% 22+7 \% 22+$ DELHI $\% 22$ andhl=paandsou $\mathrm{rce}=$ hpandaq $=$ fandaqi $=$ andaql=andoq. [Last accessed on 2011 Mar 18].

10. Available from: http://econ,worldbank.org. [Last accessed on 2011 Mar 18].

11. People with disabilities in India from commitments to outcomes. Available from: [http.//www.worldbank.org.in]. [Last accessed on 2011 Mar 18].

12. Facts and Figures. Disability India information Resources (DIIR). Available from: [http://disabilityindia.com/fact.html]. [Last accessed on 2011 Mar 18].

13. The irreversible minority. Available from: http://www.javedabidi. blogspot.com. [Last accessed on 2011 Mar 18].

14. National Polio Surveillance Project. Available from: http://www.npspindia. org/Eradication\%20strategy.asp [Lastaccessed on 2011 Aug 01].

How to cite this article: Kumar H, Gupta N. Neurological disorders and barriers for neurological rehabilitation in rural areas in Uttar Pradesh: A cross-sectional study. J Neurosci Rural Pract 2012;3:12-6.

Source of Support: Nil. Conflict of Interest: None declared. 